ISSN 2466-2232

Online ISSN 2466-2100

\title{
$\mathrm{Sn}$ 휘스커 성장에 미치는 Air-HAST 조건의 영향
}

\author{
오철민 ${ }^{*}$ 오상주 ${ }^{*}$ 김다정* · 홍원식* · 김근수**, \\ *전자부품연구원 융복합전자소재연구센터 \\ **호서대학교 신소재공학과
}

\section{Effect of Air-HAST Conditions on Sn Whisker Growth}

\author{
Chulmin Oh*, Sangjoo Oh*, Dajung Kim*, Won Sik Hong*, and Keun-Soo Kim**, ${ }^{*}$ \\ *Electronic Convergence Materials \& Device Research Center, KETI, Gyeonggi-do, 13509, Korea \\ **Dept. of Mater. Sci. \& Eng., Hoseo University, Dangjin, 31702, Korea
}

$\uparrow$ Corresponding author : keunsookim@hoseo.edu

(Received March 13, 2019 ; Revised April 10, 2019 ; Accepted April 15, 2019)

\begin{abstract}
Sn whiskers are one of the major causes of failure in fine-pitch electronics because of the short distance between the leads in an electronic package. In various whisker mechanisms, it takes a long time to grow a whisker due to $\mathrm{Sn}$ corrosion because the temperature is limited to below $100^{\circ} \mathrm{C}$ in high humidity. In the highly accelerated temperature and humidity stress test (HAST), the corrosion phenomenon rarely occurred because of the little air inside the chamber. Therefore, air is needed in the whisker accelerating test to meet the same whisker mechanism under high temperature and humidity conditions. In this study, an Air-HAST with air inputs in the chamber with highly temperature and humidity was introduced. Whisker growth was accelerated with temperatures at $130^{\circ} \mathrm{C}$ and various air pressures using the thin quad flat package (TQFP) sample with Sn plating lead. The whisker growth in the Air-HAST, HAST, and high temperature and high humidity test $\left(85^{\circ} \mathrm{C}, 85 \%\right.$ R.H. $)$ was compared by plotting each growth length and number of whiskers. The accelerated relationships of whisker growth under the various test conditions will help the electronic industry meet the short development cycles.
\end{abstract}

Key Words : Sn whisker, Air-HAST, $85^{\circ} \mathrm{C} / 85 \% \mathrm{RH}, \mathrm{HAST}$, TQFP

\section{1. 서 론}

Sn 휘스커(whisker)는 전자부품의 외부전극(단자재 료 등) 도금과 무연솔더에서 발생하는 가늘고 긴 형상 의 결정으로 대기 중의 상온에서도 성장할 수 있으며, 각종 온도 및 습도 분위기에서 길게 성장할 수 있다 ${ }^{1-4)}$. $\mathrm{Sn}$ 휘스커를 평가하는 시험방법은 IPC(Institute for Interconnecting and Packaging Electronic Circuits) ${ }^{5)}$, JEDEC(Joint Electron Device Engineering Council) 6-7), JEITA(Japan Electronics and Information Technology Industries Association $)^{8-9)}$ 의 규격에 규 정되어 있다. 세 규격은 공통적으로 상온, 대기 중 유지
시험, 고온/고습 시험, 온도사이클 시험을 포함하고 있 다. 이 중에서 솔더 접합부의 $\mathrm{Sn}$ 휘스커 평가로 적합 한 시험은 고온/고습 시험으로 알려져 있다. JEITA가 실시한 솔더 접합부 시험 결과를 보면, $\mathrm{Br}$ 계를 플럭스 전체 함량 대비 $2 \mathrm{wt} \%$ 첨가한 $\mathrm{Sn}-3 \mathrm{Ag}-0.5 \mathrm{Cu}$ 페이스 트로 솔더링 후, $85^{\circ} \mathrm{C}, 85 \%$ R.H.의 환경에서 2000 시간 방치 시 $100 \mu \mathrm{m}$ 이상의 $\mathrm{Sn}$ 휘스커가 발생하였다고 보고하고 있다 ${ }^{10)}$. 이 조건을 기준으로 하여 습도는 $85 \%$ R.H.로 고정하고, 온도를 변화 시켜 시험을 실시 하여, Sn 휘스커 발생까지의 시간을 각 조건에서 구하면 $\mathrm{Sn}$ 휘스커 발생에 대한 예측이 가능해진다. JEITA에서 는 $85^{\circ} \mathrm{C}, 85 \%$ R.H.에서 500 시간 유지 후 솔더부에 $\mathrm{Sn}$ 휘스커가 발생하지 않으면 문제없는 것으로 판단할

Journal of Welding and Joining, Vol.37 No.2(2019) pp21-25

https://doi.org/10.5781/JWJ.2019.37.2.4 
수 있다고 보고하고 있다 ${ }^{10)}$.

고온/고습 이외에 HAST(Highly Accelerated Temperature and Humidity Stress Test)와 Air-HAST 시험을 통한 $\mathrm{Sn}$ 휘스커 시험도 차량용 전장 제품을 대 상으로 실시되고 있다 ${ }^{10-11)} \mathrm{Br}$ 계를 플럭스 전체 함량 대비 $2 \mathrm{wt} \%$ 첨가한 $\mathrm{Sn}-3 \mathrm{Ag}-0.5 \mathrm{Cu}$ 페이스트로 솔더링 후, $\operatorname{HAST}\left(110^{\circ} \mathrm{C}, 85 \%\right.$ R.H., $\left.0.1218 \mathrm{MPa} \mathrm{abs}\right)$ 환경 에서 600 시간 유지한 경우에는 $\mathrm{Sn}$ 휘스커 발생이 없었으 나, $\operatorname{Air}-\mathrm{HAST}\left(110^{\circ} \mathrm{C}, 85 \% \mathrm{RH}, 0.130 \mathrm{MPa}\right.$ (공기분압), $0.2518 \mathrm{MPa} \mathrm{abs}$ ) 환경에서는 $\mathrm{Sn}$ 휘스커가 100시간 에 $30 \mu \mathrm{m}$ 까지 성장하였다. 한편, 동일한 솔더를 $85^{\circ} \mathrm{C}$, $85 \%$ R.H. 환경에서 시험한 경우, $\mathrm{Sn}$ 휘스커가 500시 간에 $40 \mu \mathrm{m}$ 까지 성장하였다 ${ }^{10-11)}$. 하지만, HAST와 Air$\mathrm{HAST}$ 를 이용한 $\mathrm{Sn}$ 휘스커 시험 결과는 아직 충분한 데이터가 확보되지 않은 상태이므로, 다양한 검토가 필 요한 실정이다.

본 연구에서는 기존의 고온/고습 시험보다 가혹한 조 건의 온도, 습도 조건을 형성할 수 있고, 특히 공기분압 조건을 변경할 수 있는 Air-HAST 장비를 이용하여 $\mathrm{Sn}$ 휘스커 발생 및 성장거동을 검토하였다. 특히, $\mathrm{Sn}$ 휘스 커 평가에 있어서 고온/고습 시험을 대체할 수 있는 가 속 시험으로서의 적용 여부를 검토하였다.

\section{2. 실험방법}

$\mathrm{Sn}$ 휘스커 평가용 시편은 $\mathrm{Sn}$ 도금된 리드(lead)를 가진 TQFP(Thin Quad Flat Package)를 Sn-3.0Ag$0.5 \mathrm{Cu}$ 솔더를 이용하여 OSP(Organic Solderability Preservative)처리된 기판에 실장하여 제작하였다. 고
온/고습 시험(EC-46MHHP, Hitachi Co.)은 $85^{\circ} \mathrm{C}$, $85 \%$ R.H. 조건에서 최대 4000 시간, $\mathrm{HAST}$ 는 $130^{\circ} \mathrm{C}$, 85\%R.H. 조건에서, Air-HAST(PC-422R8, Hirayama Co.)는 $130^{\circ} \mathrm{C}, 85 \% \mathrm{R} . \mathrm{H}$. 조건에서 공기분압을 각 0.015 , $0.020,0.035,0.060 \mathrm{MPa}$ 로 변화 시켜 최대 300시 간까지 진행하였다. Air-HAST의 각각의 공기분압 조건 에서의 이론적 공기 밀도는 약 $130,173,303,519 \mathrm{~g} / \mathrm{m}^{3}$ 이다. Table 1에 시험 환경을 정리하였다. Air-HAST 의 공기분압은 $130^{\circ} \mathrm{C}, 85 \% \mathrm{R} . \mathrm{H}$. 조건으로 설정한 후, 외 부에 연결된 공기 노즐을 통해 공기를 주입하여 조절하였다. 주사전자현미경 (SEM, S-4800, Hitachi Co.)을 이용 하여, 각 조건에서의 상위 10 개의 $\mathrm{Sn}$ 휘스커 평균 길 이와 동일한 관찰면적 당 길이가 $10 \mu \mathrm{m}$ 이상의 $\mathrm{Sn}$ 휘스 커의 발생 수를 측정하여 비교하였다.

\section{3. 실험 결과 및 고찰}

\section{1 고온/고습 시험에서의 $\mathrm{Sn}$ 휘스커 성장거동}

Fig. 1에 고온/고습 시험 중에 발생한 $\mathrm{Sn}$ 휘스커의 대표적인 형상을 나타내었다. 일반적인 $\mathrm{Sn}$ 휘스커 형 태인 필라멘트(filament)와 노듈(nodule)이 관찰되었 고, 리드부에서 주로 발생하였다. Fig. 2에 고온/고습 시험의 유지시간별 $\mathrm{Sn}$ 휘스커의 평균 길이와 발생 수 를 나타내었다. 유지시간이 경과할수록 $\mathrm{Sn}$ 휘스커의 평 균길이가 증가함을 알 수 있다. 1000, 2000, 3000, 4000 시간 유지 후의 $\mathrm{Sn}$ 휘스커 최대 길이는 각각 24 , $27,65,62 \mu \mathrm{m}$ 로 관찰되었다. 또한 길이 $10 \mu \mathrm{m}$ 이상의 $\mathrm{Sn}$ 휘스커는 유지 시간의 경과와 함께 개수가 증가하는 것도 알 수 있었다. 고온/고습 조건에서 발생하는 $\mathrm{Sn}$

Table 1 Test conditions

\begin{tabular}{|c|c|c|c|}
\hline & $\begin{array}{c}\text { High temperature and high } \\
\text { humidity test }\end{array}$ & HAST & Air-HAST \\
\hline Conditions & $85^{\circ} \mathrm{C}, 85 \%$ R.H. & $130^{\circ} \mathrm{C}, 85 \%$ R.H. & $130^{\circ} \mathrm{C}, 85 \%$ R.H. \\
\hline $\begin{array}{c}\text { Environment } \\
\text { in chamber }\end{array}$ & Air + water vapor & water vapor & Air + water vapor \\
\hline Air density $\left(\mathrm{g} / \mathrm{m}^{3}\right)$ & $\approx 500$ & 0 & $0 \sim 500$ \\
\hline
\end{tabular}

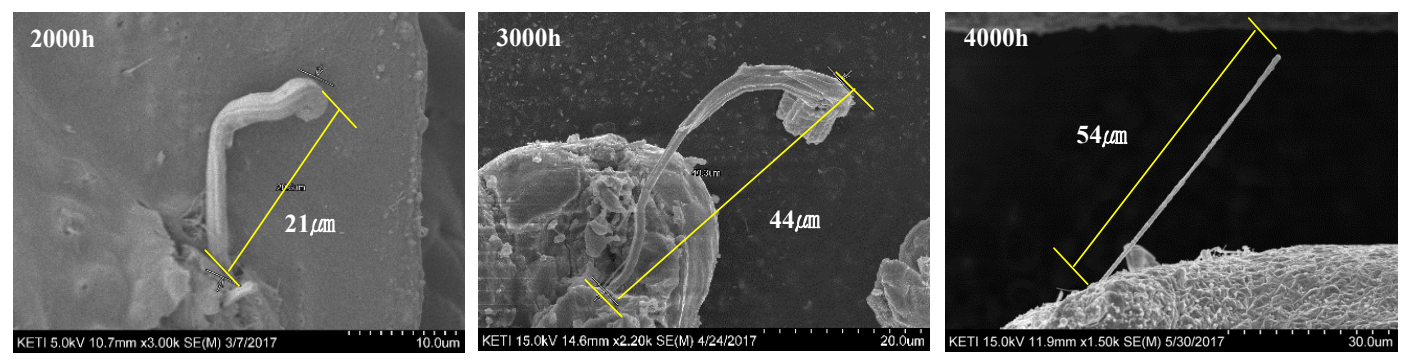

Fig. 1 SEM observations of the surfaces of samples after $85^{\circ} \mathrm{C}, 85 \%$ R.H. test 


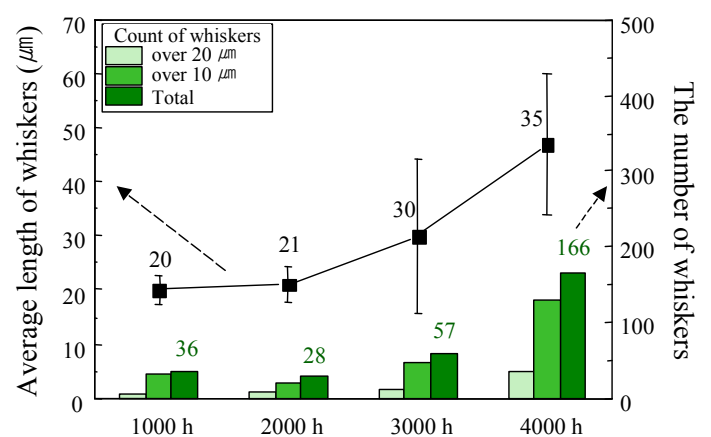

Fig. 2 Sn whisker growth behavior during $85^{\circ} \mathrm{C}, 85 \%$ R.H. test

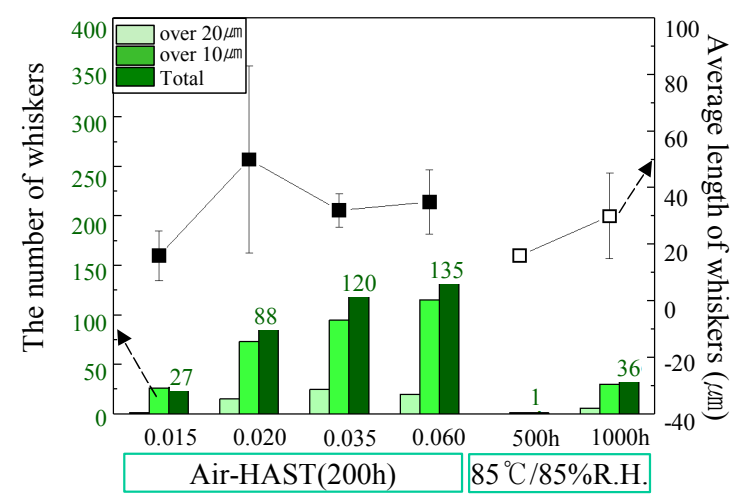

Fig. $3 \mathrm{Sn}$ whisker growth behavior during $130^{\circ} \mathrm{C}$, AirHAST

휘스커는 주원인이 $\mathrm{Sn}$ 의 산화에 의한 체적 변화로 발 생하는 응력 변화로 알려져 있다 ${ }^{10)}$. 본 연구에서도 동 일한 원인으로 인해 고온/고습 분위기에서 유지되는 시 간이 길어질수록 솔더와 리드 도금의 $\mathrm{Sn}$ 산화물 형성 이 늘어나 $\mathrm{Sn}$ 휘스커의 발생이 증가한 것으로 판단된다.

\subsection{Air-HAST에서의 Sn 휘스커 성장거동}

Fig. 3 에 $130^{\circ} \mathrm{C}, 85 \%$ R.H. 환경에서 공기분압을 달 리하였을 경우의 $\mathrm{Sn}$ 휘스커의 길이와 발생 수를 나타 내었다. 비교를 위해 고온/고습 시험 결과의 일부도 함 께 나타내었다. $\mathrm{Sn}$ 휘스커의 개수는 길이가 $10 \mu \mathrm{m}$ 이상 과 $20 \mu \mathrm{m}$ 이상으로 분류하였고, 합계도 표시하였다. Air-
$\mathrm{HAST}$ 의 경우, 공기분압이 높을수록 $\mathrm{Sn}$ 휘스커의 발 생이 많아지는 것을 알 수 있다. 각 공기분압에서 200

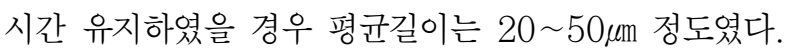
한편, 고온/고습 시험의 경우, 1000 시간까지 $\mathrm{Sn}$ 휘스 커의 발생 수는 Air-HAST 보다 적고, 평균길이는 유 사한 경향을 나타내었다. $\mathrm{Sn}$ 휘스커의 평가를 본 연구 에서 사용한 길이와 발생 수를 이용한다면, Air-HAST 가 고온/고습 시험 보다 약 $1 / 5$ 의 시험 시간으로 평가 가 가능함을 알 수 있다.

Fig. 4 에 $130^{\circ} \mathrm{C}, 85 \%$ R.H. 환경에서 공기분압을 달 리하였을 경우의 $\mathrm{Sn}$ 휘스커의 대표적인 형상을 나타내 었다. 고온/고습 시험에서 발생한 $\mathrm{Sn}$ 휘스커와 유사한 형태로, filament와 nodule 형태가 관찰되었다. 한편, 진공 상태로 평가를 진행하는 HAST에서는 Air-HAST 와 동일한 유지 시간 동안 $\mathrm{Sn}$ 휘스커는 발생하지 않았다.

\section{3 고온/고습 시험과 Air-HAST의 Sn 휘스커 평 가 비교}

$\mathrm{Sn}$ 휘스커의 평가를 고온/고습 시험을 대체하여 Air$\mathrm{HAST}$ 를 가속시험으로 이용할 경우, 고온/고습 시험과 유사한 $\mathrm{Sn}$ 휘스커 성장거동을 나타내는지, $\mathrm{Sn}$ 휘스커 의 발생 원인이 유사한지를 확인해야 한다. Fig. 5에 $130^{\circ} \mathrm{C}$ 에서 공기분압이 $0.035 \mathrm{MPa}$ 인 경우의 $\mathrm{Sn}$ 휘스

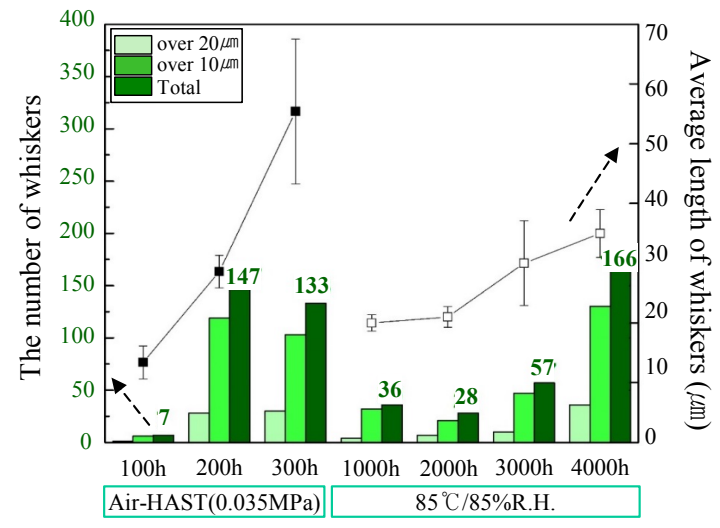

Fig. $5 \mathrm{Sn}$ whisker growth behavior during $130^{\circ} \mathrm{C}$, Air$\operatorname{HAST}(0.035 \mathrm{MPa})$
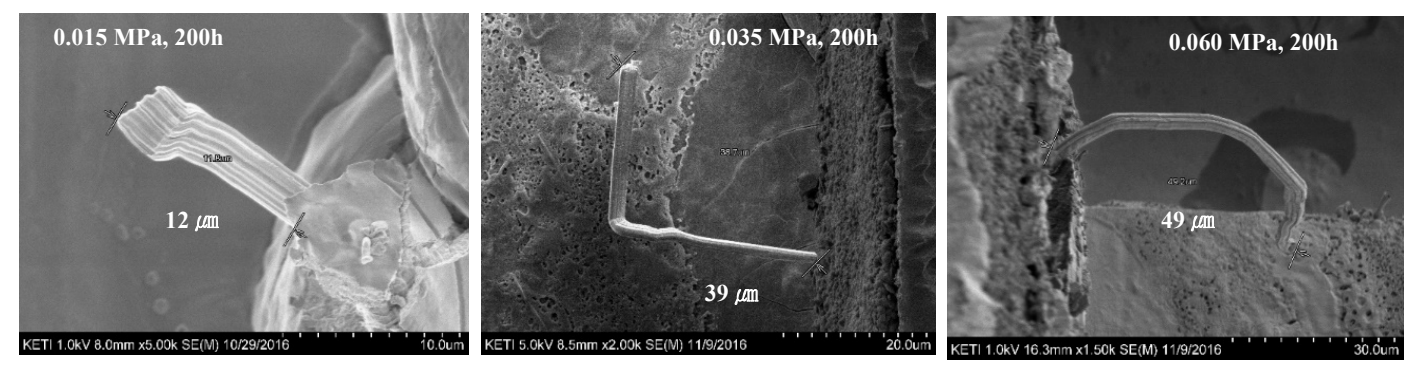

Fig. 4 SEM observations of the surfaces of samples after Air-HAST at $130^{\circ} \mathrm{C}$ 


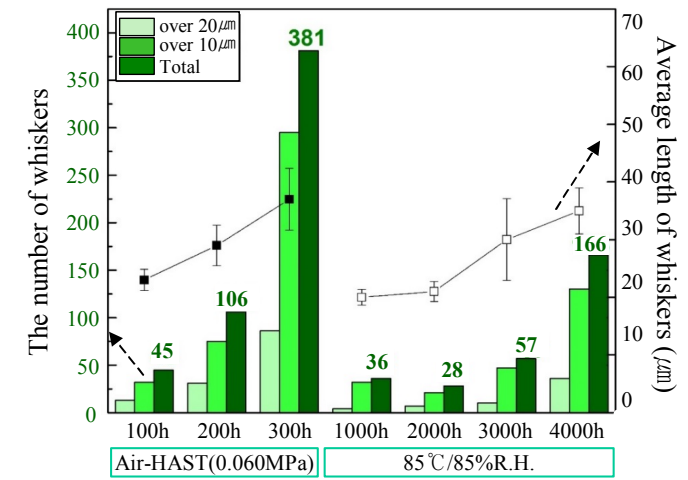

Fig. $6 \mathrm{Sn}$ whisker growth behavior during $130^{\circ} \mathrm{C}$, Air$\operatorname{HAST}(0.060 \mathrm{MPa})$.

커의 성장거동을 나타내었다. 100 시간에서는 고온/고 습 시험의 1000 시간과 비교하여 적은 수의 $\mathrm{Sn}$ 휘스 커가 발생하였고, 평균길이도 작은 것으로 관찰되었다. 200 시간 이상에서는 고온/고습 시험 4000 시간과 동 등한 수의 $\mathrm{Sn}$ 휘스커가 발생하였고, 평균길이도 유사 하거나 더 긴 것으로 나타났다. $130^{\circ} \mathrm{C}$ 에서 공기분압이 $0.060 \mathrm{MPa}$ 인 경우는 Fig. 6 에 나타낸 것과 같이 100 시간에서의 $\mathrm{Sn}$ 휘스커 평균길이는 고온/고습 시험 4000 시간의 결과와 유사하며, 200시간 이상에서는 $\mathrm{Sn}$ 휘스 커의 발생 수도 유사한 결과를 나타내었다. Air-HAST 에서는 공기분압이 증가할수록 $\mathrm{Sn}$ 휘스커의 평균길이 가 증가하는 경향을 보였고, $\mathrm{Sn}$ 휘스커의 발생 수는 큰 폭으로 증가하는 것을 알 수 있었다. 또한 본 연구 의 범위 내에서 Air-HAST의 공기분압이 증가할수록 고온/고습 시험 대비 가속성이 높아지는 경향을 나타내 었다.

위에서 설명한 것과 같이 고온/고습 분위기에서 발생 하는 $\mathrm{Sn}$ 휘스커는 $\mathrm{Sn}$ 의 산화가 주원인이다. 또한 $\mathrm{QFP}$ 등의 리드 선단부에서는 리드의 모재인 $\mathrm{Cu}$ 등이 노출 될 경우, $\mathrm{Cu}$ 와 $\mathrm{Sn}$ 이 갈바닉 전지를 형성하여 산화가 급속히 진행되는 것으로 추정되고 있다 ${ }^{10)}$. 공기분압을 거의 0에 가깝게 조정한 $\mathrm{HAST}$ 의 경우, $\mathrm{Sn}$ 의 산화가 상대적으로 적어, $\mathrm{Sn}$ 휘스커가 발생하지 않은 것으로 판단된다. Fig. 7에 Air-HAST와 고온/고습 시험에서 발생한 $\mathrm{Sn}$ 휘스커 주변의 단면 미세조직을 나타내었다. 양쪽 모두에서 $\mathrm{Sn}$ 의 산화물이 발견되었고, $\mathrm{Sn}$ 휘스커 주변의 미세조직이 유사하여 동일한 메커니즘에 의한 성장으로 예상된다.

\section{4. 결 론}

본 연구에서는 고온/고습 환경에서 성장하는 $\mathrm{Sn}$ 휘 스커의 평가를 위해 사용되는 $85^{\circ} \mathrm{C}, 85 \% \mathrm{R} . \mathrm{H}$. 시험의
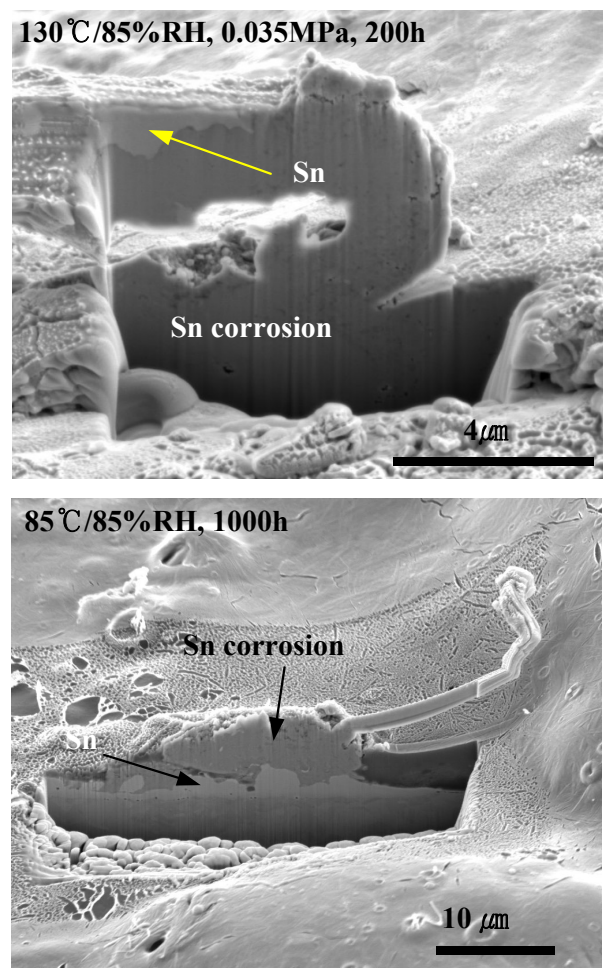

Fig. 7 Cross sectional images of Sn plating around the Sn whisker

평가 기간을 단축하기 위한 방법으로 보다 가혹한 조건 이며, 공기가 잔존하는 Air-HAST를 적용하여 검토하 였다. 평가 중 진공 상태를 유지하는 일반적인 HAST 는 본 연구의 범위 내에서 $\mathrm{Sn}$ 휘스커가 발생하지 않았 으나, Air-HAST는 공기분압 $0.035 \mathrm{MPa}$ 이상의 조건 에서 비교적 단시간에 $\mathrm{Sn}$ 휘스커의 성장이 관찰되었으 며, $85^{\circ} \mathrm{C}, 85 \%$ R.H. 보다 5 배 정도의 가속성이 있음을 확인하였다. 따라서 Air-HAST는 솔더와 $\mathrm{Sn}$ 계 도금층 의 $\mathrm{Sn}$ 산화에 의해 발생하는 $\mathrm{Sn}$ 휘스커를 단시간에 평 가할 수 있는 유용한 시험법으로 판단된다.

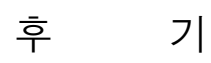

이 논문은 신업통상자원부 우수기술연구센터사업(10076304) 의 지원을 받아 수행된 내용입니다.

ORCID: Chulmin Oh: http://orcid.org/0000-0003-4609-9408 ORCID: Snagjoo Oh: http://orcid.org/0000-0003-1815-6946 ORCID: Dajung Kim: http://orcid.org/0000-0002-8330-9470 ORCID: Won Sik Hong: http://orcid.org/0000-0001-8398-177X ORCID: Keun-Soo Kim: http://orcid.org/0000-0002-8275-8362

\section{References}

1. Benchmarking and Best Practices Center of Excellence, $\mathrm{Pb}$ free Electronics Research Manhattan Project, $A C I$ 
Technologies Inc. (2009)

2. K. S. Kim, Sn Whisker Research Trend in Japan, J. Microelectron. Packag. Soc., 19(4) (2012), 7-12 http://dx.doi.org/10.6117/kmeps.2012.19.4.007

3. K. S. Kim, Mitigation Methods of Sn Whisker Growth on Pure Sn Plating, Journal of KWJS, 31(3) (2013), 185-189 http://dx.doi.org/10.5781/KWJS.2013.31.3.21

4. C. M. Oh, et. al., The Growth Mechanism and Mitigation Method of Sn Whisker, Journal of KWJS, 29(4) (2011), 365-372

http://dx.doi.org/10.5781/KWJS.2011.29.4.365

5. IEC60068-2-82, Whisker Test Methods for Electronics and Electric Components, IEC Standard, (2007)

6. JESD22A121A, Test Method for Measuring Whisker Growth on Tin and Tin Alloy Surface Finishes, JEDEC/IPC Joint Publication, (2008)
7. JESD201, Environmental Acceptance Requirement for Tin Whisker Susceptibility of Tin and Tin Alloy Surface Finishes, JEDEC/IPC Joint Publication, (2006)

8. ET-7410, Whisker Test Methods on Components for Use in Electrical and Electronic Equipment, JEITA Standard, (2005)

9. RC-5241, Whisker Test Methods on Connectors for Use in Electrical and Electronic Equipment, JEITA Standard, (2007)

10. Japan Electronics and Information Technology Industries Association, Guideline for Selection of Lead-Free Materials for Tin-Whisker Mitigation, (2010)

11. T. Tsukui, et. al., Study on Flux and Alloy of Lead Free Solder with Mitigation Effect and Consideration for Acceleration Test Method, J. Japan Institute of Electronics Packaging, 15(5) (2012), 404-416 http://dx.doi.org/10.5104/jiep.15.404 